Research Article

\title{
The Locating Chromatic Number of Book Graph
}

\author{
Nur Inayah $(\mathbb{D}$, Wisnu Aribowo $\mathbb{D}$, and Maiyudi Mariska Windra Yahya \\ Department of Mathematics, State Islamic University Syarif Hidayatullah Jakarta, South Tangerang, Indonesia
}

Correspondence should be addressed to Nur Inayah; nur.inayah@uinjkt.ac.id

Received 18 April 2021; Accepted 7 October 2021; Published 24 November 2021

Academic Editor: Elena Guardo

Copyright (c) 2021 Nur Inayah et al. This is an open access article distributed under the Creative Commons Attribution License, which permits unrestricted use, distribution, and reproduction in any medium, provided the original work is properly cited.

Let $G=(V(G), E(G))$ be a connected graph and $\mathbf{c}: \mathbf{V}(\mathbf{G}) \longrightarrow\{1,2, \ldots, \mathbf{k}\}$ be a proper $\mathbf{k}$-coloring of $\mathbf{G}$. Let $\Pi$ be a partition of vertices of $\mathbf{G}$ induced by the coloring $\mathbf{c}$. We define the color $\operatorname{code} c_{\Pi}(v)$ of a vertex $\mathbf{v} \in \mathbf{V}(\mathbf{G})$ as an ordered $\mathbf{k}$-tuple that contains the distance between each partition to the vertex $\mathbf{v}$. If distinct vertices have distinct color code, then $\mathbf{c}$ is called a locating $\mathbf{k}$-coloring of $\mathbf{G}$. The locating chromatic number of $\mathbf{G}$ is the smallest $\mathbf{k}$ such that $\mathbf{G}$ has a locating $\mathbf{k}$-coloring. In this paper, we determine the locating chromatic number of book graph.

\section{Introduction}

All graphs considered in this paper are assumed to be simple, connected, and undirected. Let $G=(V(G), E(G))$ be a graph with vertex set $V(G)$ and edge set $E(G)$. By $P_{n}$ and $S_{n}$, we denote a path on $n$ vertices and a star on $n+1$ vertices, respectively. The distance, $d(u, v)$, between two vertices $u$ and $v$ is defined as the length of the shortest path connecting them in $G$.

For a graph $G$ and a positive integer $k$, a coloring $c: V(G) \longrightarrow\{1,2, \ldots, k\}$ with $c(u) \neq c(v)$ for every two adjacent vertices $u$ and $v$ is called a proper $k$-coloring of $G$. Let $\Pi=\left\{C_{1}, C_{2}, \ldots, C_{k}\right\}$ be a partition of vertices of $G$ induced by the coloring $c$, where $C_{i}$ denotes the set of vertices receiving color $i$. A color code, $c_{\Pi}(v)$, of a vertex $v$ with respect to $\Pi$ is an ordered $k$-tuple $\left(d\left(u, C_{1}\right)\right.$, $\left.d\left(u, C_{2}\right), \ldots, d\left(u, C_{k}\right)\right)$, where $\quad d\left(u, C_{i}\right)=\min$ $\left\{d(u, x): x \in C_{i}\right\}$ for every $i=1,2, \ldots, k$. If distinct vertices have distinct color codes, then $c$ is called a locating $k$-coloring of $G$. The locating chromatic number of $G$, denoted by $\chi_{L}(G)$, is the smallest $k$ for which $G$ has a locating $k$-coloring.

The concept of locating chromatic number of a graph was introduced in 2002 by Chatrand et al. [1]. This concept is derived from the graph partition dimension and graph coloring. The study about locating chromatic number of a graph has grown constantly. Chartrand et al. [1] determined the locating chromatic number of some well-known graph classes such as paths with $\chi_{L}\left(P_{n}\right)=3$ for $n \geq 3$, cycles with $\chi_{L}\left(C_{n}\right)=3$ for odd $n \geq 3$ and $\chi_{L}\left(C_{n}\right)=4$ for even $n \geq 4$, and double stars with $\chi_{L}\left(S_{m, n}\right)=n+1$ for $1 \leq m \leq n$ and $n \geq 2$. In [2], Behtoei and Omoomi investigated the locating chromatic number for Cartesian product of graphs. Welyyanti et al. [3] discussed the locating chromatic number for disconnected graphs. Furthermore, the locating chromatic number of spinner graph was proved by Rianti and Narwen [4].

Let $G$ and $H$ be two given graphs. The Cartesian product of $G$ and $H$, denoted by $G \times H$, is a graph having the vertex set $V(G \times H)=V(G) \times V(H)$ such that two distinct vertices $\left(u_{1}, v_{1}\right)$ and $\left(u_{2}, v_{2}\right)$ are adjacent if and only if $u_{1}=u_{2}$ and $v_{1} v_{2} \in E(H)$ or $v_{1}=v_{2}$ and $u_{1} u_{2} \in E(G)$.

For a positive integer $n \geq 1$, a book graph, denoted by $B_{n}$, is a graph obtained from $n$ copies of a cycle of order 4 sharing one common edge. The book graph $B_{n}$ is also called the Cartesian product $P_{2} \times S_{n}$. In this paper, we investigate the locating chromatic number of book graph.

The following theorem proved by Chartrand et al. [1] is useful in determining the locating chromatic number of a graph.

Theorem 1. Let $c$ be a locating coloring in a connected graph $G$ and $N(v)$ be the set of vertices adjacent to $v$. If $u$ and $v$ are distinct vertices of $G$ such that $d(u, w)=d(v, w)$ for all $w \in V(G)-\{u, v\}$, then $c(u) \neq c(v)$. In particular, if $u$ and $v$ are nonadjacent vertices of $G$ such that $N(u)=N(v)$, then $c(u) \neq c(v)$. 


\section{Result and Discussion}

In this section, we determine the exact value for the locating chromatic number of book graphs. Let $B_{n}$ be a book graph with the vertex set $V\left(B_{n}\right)=\left\{u_{i}, v_{i}: i=0,1, \ldots, n\right\}$ and the edge set $E\left(B_{n}\right)=\left\{u_{i} v_{i}: i=0,1, \ldots, n\right\} \cup\left\{u_{0} u_{i}, v_{0} v_{i}: i=1,2\right.$, $\ldots, n\}$.

Two observations below follow from definition of proper coloring.

Observation 1. Let $c$ be a locating coloring of the book graph $B_{n}, n \geq 1$. Then, $c\left(u_{i}\right) \neq c\left(v_{i}\right)$ for $i=0,1, \ldots, n$.

Observation 2. Let $c$ be a locating coloring of the book graph $B_{n}, \quad n \geq 1$. Then, $c\left(u_{0}\right) \neq c\left(u_{i}\right)$ and $c\left(v_{0}\right) \neq c\left(v_{i}\right)$ for $i=1,2, \ldots, n$.

Lemma 1. Let $c$ be a locating coloring of the book graph $B_{n}$, $n \geq 1$. Then, $\left(c\left(u_{i}\right), c\left(v_{i}\right)\right) \neq\left(c\left(u_{j}\right), c\left(v_{j}\right)\right)$ for $1 \leq i \neq j \leq n$.

Proof. Assume that $\left(c\left(u_{i}\right), c\left(v_{i}\right)\right)=\left(c\left(u_{j}\right), c\left(v_{j}\right)\right)$ for some $i$ and $j, i \neq j$. This means that $c\left(u_{i}\right)=c\left(u_{j}\right)$ and $c\left(v_{i}\right)=c\left(v_{j}\right)$. We know that $d\left(u_{i}, x\right)=d\left(u_{j}, x\right)$ for every $x \in V\left(B_{n}\right)-\left\{u_{i}, u_{j}, v_{i}, v_{j}\right\}$. As $c\left(v_{i}\right)=c\left(v_{j}\right)$ and $d\left(u_{i}, v_{i}\right)=$ $d\left(u_{j}, v_{j}\right)=1$, regardless the color of $x$, we have $c_{\Pi}\left(u_{i}\right)=$ $c_{\Pi}\left(u_{j}\right)$, a contradiction.

Lemma 2. Let $c$ be a locating $k$-coloring of the book graph $B_{n}$, for $k \geq 4$ and $n \geq 1$. Then,

$$
n \leq 2\left(\begin{array}{c}
k-2 \\
2
\end{array}\right)+2(k-1)-1 \text {. }
$$

Proof. Start coloring the graph by giving color $C_{1}$ and $C_{2}$ for the vertices in the middle, that is, $c\left(u_{0}\right)=C_{1}$ and $c\left(v_{0}\right)=C_{2}$. From Observation 2, we know that we should have $c\left(u_{i}\right) \neq C_{1}$ and $c\left(v_{i}\right) \neq C_{2}$ for each $i=1,2, \ldots, n$.

Case 1. Assume $\left\{c\left(u_{a}\right), c\left(v_{a}\right)\right\}$ does not contain either $C_{1}$ or $C_{2}$. Thus, the total color that we can choose is $\left(\begin{array}{c}k-2 \\ 2\end{array}\right) \times 2$ because every outer part of sheets requires 2 different colors from observation 1 , which means there are $\left(\begin{array}{c}k-2 \\ 2\end{array}\right)$ possibilities. But, since $c\left(u_{a}\right)$ and $c\left(v_{a}\right)$ are reversible without any consequences, the total that can be obtained is $\left(\begin{array}{c}k-2 \\ 2\end{array}\right) \times 2$.

Case 2. If $c\left(u_{a}\right)=2$, the total possibility of the colors being used is $(k-1)$ because $c\left(v_{a}\right)$ can only be given with $1,3,4, \ldots, k$, where only one color can be used by book graph $B_{n}$ for $n \geq 2$. The illustration is shown in Figure 1 .

Case 3. If $c\left(v_{a}\right)=1$, the total colors can be used are $(k-1)$ because $c\left(u_{a}\right)$ can only be given by color $2,3,4, \ldots, k$, where only two colors can be used on book graph $B_{n}$ for $n \geq 2$. The illustration is shown in Figure 2.

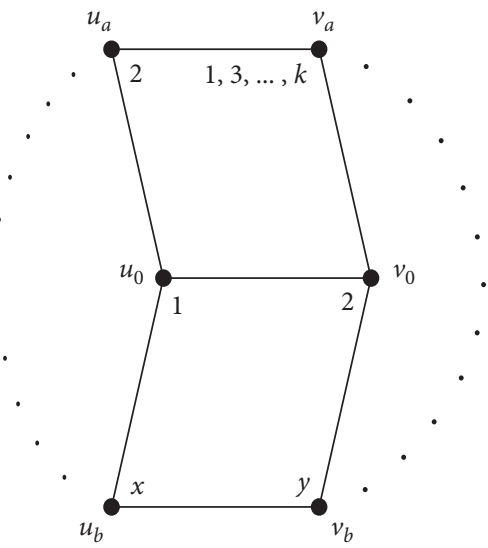

Figure 1: Illustration of Case 2.

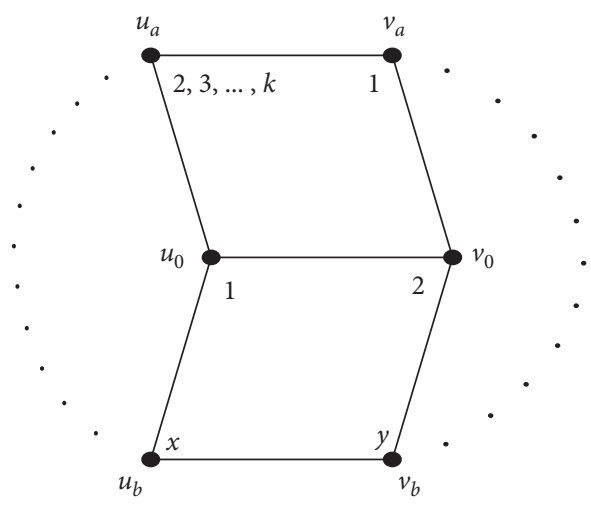

FIGURE 2: Illustration of Case 3.

Since the coloring $c\left(v_{a}\right)=1$ and $c\left(u_{a}\right)=2$ have been used in Case 2, then the coloring is not reusable, and thus, the total coloring is $(k-1)-1$. If uses $k$ colors, then $\chi_{L}\left(B_{n}\right)$ must satisfy the following

$$
\begin{aligned}
& n \leq 2\left(\begin{array}{c}
k-2 \\
2
\end{array}\right)+(k-1)+(k-1)-1 \\
& n \leq 2\left(\begin{array}{c}
k-2 \\
2
\end{array}\right)+2(k-1)-1 .
\end{aligned}
$$

Theorem 2. Locating chromatic number of book graph $B_{n}$ is

$$
\chi_{L}\left(B_{n}\right)=\min \left\{k: n \leq 2\left(\begin{array}{c}
k-2 \\
2
\end{array}\right)+2(k-1)-1\right\},
$$

$$
\text { for } k \geq 4 \text {. }
$$

Proof. Firstly, we will prove the existence of $\chi_{L}\left(B_{n}\right)$. We can clearly see that $\left\{k: n \leq 2\left(\begin{array}{c}k-2 \\ 2\end{array}\right)+2(k-1)-1\right\}$ is the subset from a set of real numbers. So from the well-ordering principle, the set must have the smallest element, say

$$
k^{*}:=\min \left\{k: n \leq 2\left(\begin{array}{c}
k-2 \\
2
\end{array}\right)+2(k-1)-1\right\} \text {, }
$$


that yields

$$
\left(k^{*}-1\right) \geq \min \left\{k: n \leq 2\left(\begin{array}{c}
k-2 \\
2
\end{array}\right)+2(k-1)-1\right\}=k^{*} .
$$

It was contradiction, which means it is impossible that the locating chromatic of book graph has a coloring for $\left(k^{*}-1\right)$ colors. It should be

$$
\begin{array}{r}
\chi_{L}\left(B_{n}\right)=k^{*}=\min \left\{k: n \leq 2\left(\begin{array}{c}
k-2 \\
2
\end{array}\right)+2(k-1)-1\right\}, \\
\text { for } k \geq 4 .
\end{array}
$$

Corollary 1. Locating chromatic number of book graph $B_{n}$ is

$$
\chi_{L}\left(B_{n}\right)=\left\lceil\sqrt{n-\frac{3}{4}}+\frac{3}{2}\right\rceil \text {. }
$$

Proof. Let $k$ be the color needed for locating chromatic of book graph $B_{n}$, then

$$
\begin{aligned}
& n \leq 2\left(\begin{array}{c}
k-2 \\
2
\end{array}\right)+2(k-1)-1, \\
& n \leq \frac{(k-2)(k-3)}{2} \times 2+2 k-2-1,
\end{aligned}
$$

$$
\begin{aligned}
\left(k^{2}-5 k+6+2 k-3\right) & \geq n, \\
k^{2}-3 k+3 & \geq n, \\
\left(k-\frac{3}{2}\right)^{2}-\frac{9}{4}+3 & \geq n, \\
\left(k-\frac{3}{2}\right)^{2}+\frac{3}{4} & \geq n, \\
\left(k-\frac{3}{2}\right)^{2} & \geq n-\frac{3}{4}, \\
k & \geq \sqrt{n-\frac{3}{4}}+\frac{3}{2} .
\end{aligned}
$$

Then, the smallest possible $k$ is

$$
k_{\min }=\left\lceil\sqrt{n-\frac{3}{4}}+\frac{3}{2}\right\rceil \text {. }
$$

\section{Conclusion}

The locating chromatic number of book graph that has been found is

found is

$$
\begin{array}{r}
\chi_{L}\left(B_{n}\right)=k^{*}=\min \left\{k: n \leq\left(\begin{array}{c}
k-2 \\
2
\end{array}\right)+2(k-1)-1\right\}, \\
\text { for } k \geq 4,
\end{array}
$$

or

$$
k_{\min }=\left\lceil\sqrt{n-\frac{3}{4}}+\frac{3}{2}\right\rceil \text {. }
$$

\section{Data Availability}

No data were used to support this study.

\section{Conflicts of Interest}

The authors declare that they have no conflicts of interest.

\section{Acknowledgments}

This work was supported by the Center of Research and Publication of Syarif Hidayatullah State Islamic University Jakarta.

\section{References}

[1] G. Chartrand, D. Erwin, M. Henning, P. Slater, and P. Zhang, "The locating-chromatic number of a graph," Bulletin of the ICA, vol. 36, pp. 89-101, 2002.

[2] A. Behtoei and B. Omoomi, "On the locating chromatic number of the cartesian product of graphs," Ars Combinatoria, vol. 126, pp. 221-235, 2012.

[3] D. Welyyanti, E. T. Baskoro, R. Simanjuntak, and S. Uttunggadewa, "The locating-chromatic number of disconnected graphs," Far East Journal of Mathematical Sciences, vol. 94, no. 2, pp. 169-182, 2014.

[4] C. D. Rianti and Narwen, "Bilangan kromatik lokasi dari graf spinner," Jurnal Matematika UNAND, vol. VII, no. 4, pp. 19-23, 2018. 